\title{
Baclofen and trazodone: New culprits in toxic epidermal necrolysis
}

\author{
N Sam Huq MD, Janet E Sproat MSc MD FRCSC \\ McMaster University, Hamilton, Ontario
}

NS Huq, JE Sproat. Baclofen and trazodone: New culprits in toxic epidermal necrolysis. Can J Plast Surg 1996;4(2):123-124. Two case reports involving drugs suspected of causing toxic epidermal necrolysis, that have not been previously implicated in this rare cutaneous drug reaction, are presented.

Key Words: Baclofen, Toxic epidermal necrolysis, Trazodone

\section{Baclofen et trazodone : de nouveaux coupables dans l'érythrodermie bulleuse avec épidermolyse}

RÉSUMÉ : On présente ici deux rapports de cas impliquant des médicaments soupçonnés d'être en cause dans l'érythrodermie bulleuse avec épidermolyse. Ces médicaments n'avaient encore jamais été associés à une telle réaction médicamenteuse cutanée.

Toxic epidermal necrolysis (TEN) is a rare cutaneous drug reaction with an associated mortality of $20 \%$ to $30 \%$ with modern treatment (1-5). In determining the culprit drug, it is essential to obtain a careful, detailed history of all medications taken and at what time intervals with respect to the first cutaneous manifestations of TEN (6). In some instances, the etiology may be from certain viral infections (cytomegalovirus, Epstein-Barr virus, herpes simplex virus, herpes zoster virus and human immunodeficiency virus), graft-versus-host disease, and malignancies $(1,2)$.

A retrospective chart analysis of all patients who were diagnosed with TEN in Hamilton, Ontario from 1985 to 1994 was carried out. The assessment of drug responsibility followed the methods proposed by Roujeau et al (1) for reporting adverse drug reactions. Introduction of a drug less than three weeks before the time of diagnosis was considered 'highly suggestive' of its responsibility, while withdrawal of a drug more than three weeks before diagnosis was considered 'incompatible'.

The following two cases involve drugs suspected of causing TEN that have not yet been reported.

\section{CASE 1}

A 36-year-old white male was being treated with methadone for known intravenous drug abuse of cocaine and heroin. He tested negative for HIV infection in December 1992. In mid January the following year, he was started on trazodone for depression and two weeks after this he developed a diffuse, painful erythematous rash, 
with fever. On admission, the patient had a viral upper respiratory tract infection and was taking acetaminophen-phenylpropanolamine (Sinutab ${ }^{\circledR}$ ) orally, as he had in the past, but no other medications. He had no previous allergies or skin reactions. Desquamation of almost $100 \%$ of the total body surface area began two days after the onset of the rash and the diagnosis was confirmed on day 3 when skin biopsy showed epidermal necrosis. Wound cultures grew Staphylococcus aureus and Candida species. The patient was treated with topical pigskin allografts, chlorhexidine, bacitracin and framycetin. He was started on intravenous corticosteroids, but this was discontinued upon a plastic surgery consultation, and the patient was transferred to the burn unit. He required intubation for adult respiratory distress syndrome, became septic and responded to cloxacillin and ceftazidime. He also had some difficulty with narcotic withdrawal. The skin lesions had completely healed after 20 days of treatment and he was discharged with no persisting sequelae found in follow-up at three months.

\section{CASE 2}

A 22-year-old previously healthy East Indian man had mechanical low back pain and was prescribed baclofen by his family physician. He had no previous allergies or skin reactions. Within three days from first ingestion, he developed a mild erythematous rash which progressed over the following week to become more diffuse and severely painful. He was admitted to the burn unit and was topically treated with pigskin allografts and framycetin to the $45 \%$ of total body surface area desquamated. He received $80 \mathrm{mg}$ of prednisone daily by mouth. Skin biopsy confirmed the diagnosis of TEN. Skin cultures grew $S$ aureus and Escherichia coli and he was treated with cloxacillin. He had a relatively uncomplicated course in hospital and skin lesions healed 10 days following admission. There were no persisting sequelae on follow-up at three months.

\section{DISCUSSION}

With the exception of trazodone and baclofen, these two patients had no other drug exposure within three weeks before the onset of symptoms, other than the acetaminophen-phenylpropanolamine mentioned in case 1 which the patient had taken numerous times in the past without difficulty. The patients had no other viral exposure known to cause or to be associated with TEN. They had no recent radiation exposure, neoplasms, vaccinations or other recognizable etiological causes. Thus there is a high index of suspicion that the drugs trazodone and baclofen were a possible cause of TEN in cases 1 and 2, respectively. As new medications are continually developed, and the trend of polypharmacy increases, it can be expected that physicians will encounter more drugs being implicated in the etiology of TEN.

\section{REFERENCES}

1. Roujeau J-C, Guillaume J-C, Fabre J-P, et al. Toxic epidermal necrolysis (Lyell syndrome): Incidence and drug etiology in France, 1981-1985. Arch Dermatol 1990;126:37-42. 
2. Halebian PH, Madden MR, Finklestein JL, et al. Improved burn center survival of patients with toxic epidermal necrolysis managed without corticosteroids. Ann Surg 1986;204:503-12.

3. Heimbach DM, Loren LH, Marvin JA, et al. Toxic epidermal necrolysis: A step forward in treatment. JAMA 1987;257:2171-5.

4. Revuz J, Penso D, Roujeau J-C, et al. Toxic epidermal necrolysis: Clinical findings and prognosis factors in 87 patients. Arch Dermatol 1987;123:1160-5.

5. Guillaume J-C, Roujeau J-C, Revuz J, et al. The culprit drugs in 87 cases of toxic epidermal necrolysis (Lyell's syndrome). Arch Dermatol 1987;123:1166-70.

6. Avakian R, Flowers FP, Araujo OE, et al. Toxic epidermal necrolysis: A review. J Am Acad Dermatol 1991;25:69-79. 